\title{
Francisella tularensis subsp. novicida isolated from a human in Arizona
}

\author{
Dawn N Birdsell ${ }^{1}$, Tasha Stewart ${ }^{2}$, Amy J Vogler ${ }^{1}$, Elisabeth Lawaczeck ${ }^{3}$, \\ Alisa Diggs $^{2}$, Tammy L Sylvester ${ }^{2}$, Jordan L Buchhagen ${ }^{1,4}$, \\ Raymond K Auerbach ${ }^{1,5}$, Paul Keim ${ }^{1,4}$ and David M Wagner*1
}

\begin{abstract}
Address: ${ }^{1}$ Center for Microbial Genetics and Genomics, Northern Arizona University, Flagstaff, AZ 86011-4073, USA, ${ }^{2}$ Maricopa County Department of Public Health, Phoenix, AZ 85012, USA, ${ }^{3}$ Arizona Department of Health Services, Phoenix, AZ 85007, USA, ${ }^{4}$ Translational Genomics Research Institute, Phoenix, AZ 85004, USA and ${ }^{5}$ Program in Computational Biology and Bioinformatics, Yale University, New Haven, CT 06520, USA

Email: Dawn N Birdsell - Dawn.Birdsell@nau.edu; Tasha Stewart - STEWART@azdhs.gov; Amy J Vogler - Amy.Vogler@nau.edu; Elisabeth Lawaczeck - lawacze@azdhs.gov; Alisa Diggs - alisadiggs@mail.maricopa.gov;

Tammy L Sylvester - tammysylvester@mail.maricopa.gov; Jordan L Buchhagen - jbuchhagen@tgen.org;

Raymond K Auerbach - Raymond.Auerbach@yale.edu; Paul Keim - Paul.Keim@nau.edu; David M Wagner* - Dave.Wagner@nau.edu

* Corresponding author
\end{abstract}

Published: 6 November 2009

BMC Research Notes 2009, 2:223 doi:10.1 186/1756-0500-2-223

This article is available from: http://www.biomedcentral.com/1756-0500/2/223

(c) 2009 Wagner et al; licensee BioMed Central Ltd.

This is an Open Access article distributed under the terms of the Creative Commons Attribution License (http://creativecommons.org/licenses/by/2.0), which permits unrestricted use, distribution, and reproduction in any medium, provided the original work is properly cited.
Received: 9 July 2009

Accepted: 6 November 2009

\begin{abstract}
Background: Francisella tularensis is the etiologic agent of tularemia and is classified as a select agent by the Centers for Disease Control and Prevention. Currently four known subspecies of $F$. tularensis that differ in virulence and geographical distribution are recognized:tularensis (type $A$ ), holarctica (type B), mediasiatica, and novicida. Because of the Select Agent status and differences in virulence and geographical location, the molecular analysis of any clinical case of tularemia is of particular interest. We analyzed an unusual Francisella clinical isolate from a human infection in Arizona using multiple DNA-based approaches.
\end{abstract}

Findings: We report that the isolate is $F$. tularensis subsp. novicida, a subspecies that is rarely isolated.

Conclusion: The rarity of this novicida subspecies in clinical settings makes each case study important for our understanding of its role in disease and its genetic relationship with other $F$. tularensis subspecies.

\section{Background}

Tularemia is an incapacitating disease that presents in two main forms: pneumonic or ulceroglandular. The causative agent is the bacterium Francisella tularensis. Without antibiotic treatment, death occurs in $30 \%-60 \%$ of victims with the pneumonic form [1]. Because of this high mortality and its low infectious dose, F. tularensis was historically targeted for biological weapons development by the governments of the United States, Japan, and the former Soviet Union [1]. As a result, it is currently classified as a Category A Select Agent by the Centers for Disease Control and Prevention (CDC). Small animals (e.g., lagomorphs and rodents) may serve as hosts for $F$. tularensis and arthropods can serve as biological vectors for transmission. Although humans commonly acquire the infection through insect bites or handling of infected tissue, direct 
contact with environments where F. tularensis persists can comprise another source of infection [2].

Although a new species, F. piscicida, was recently identified [3], the three most commonly studied species within the Francisella genus are F. tularensis, F. novicida, and F. philomiragia [2]. F. tularensis is officially divided into three subspecies: tularensis (type A), which is further divided into subpopulations A.I and A.II [4,5]; holarctica (type B), and mediasiatica [2]. According to Staples et al. [6], these subspecies and subpopulations differ in pathogenicity, with $F$. tularensis subsp. tularensis subpopulation A.I more virulent than $F$. tularensis subsp. holarctica, which is more virulent than $F$. tularensis subsp. tularensis subpopulation A.II. F. tularensis subsp. mediasiatica has been reported to have virulence similar to F. tularensis subsp. holarctica [2], but was not included in the aforementioned study [6]. The rarely isolated $F$. novicida appears less virulent than $F$. tularensis [2], but has been shown to cause disease [7-10]. $F$. novicida is also genetically similar to $F$. tularensis, causing many to classify it as a fourth subspecies of $F$. tularensis $[2,5,11,12]$, which this study also will do. F. philomiragia also causes human disease, usually in victims of neardrowning or immunocompromised individuals $[8,13]$.

In addition to these recognized species and subspecies, PCR-based analyses of environmental samples have detected Francisella-like organisms in air, water, and soil $[14,15]$. These findings indicate the existence of a diverse group of organisms that are not well accounted for in the current taxonomy [2]. These Francisella-like organisms may or may not cause disease [14], though a recent report of two Francisella-like organisms from human infections with $16 \mathrm{~S}$ rDNA sequences similar to those of the environmental Francisella-like organisms suggests the potential for human infection [16]. The deeper phylogenetic structure of the Francisella genus remains poorly understood but will improve as more detailed phylogenetic information is obtained from additional genomic sequences [2].

Because of pathogenicity differences, as well as the Select Agent status of $F$. tularensis (including F. tularensis subsp. novicida), correctly identifying clinical isolates as F. tularensis and assigning them to particular subspecies and/or molecular groups within $F$. tularensis is desirable. Biochemical-based subtyping methods are not ideal because of their labor intensiveness and because the results often are non-definitive. DNA-based assays provide the most robust means of accomplishing this task [2]. Molecular assays capable of assigning unknown isolates to F. tularensis subsp. tularensis or holarctica have been developed [1719], but less attention has been paid to F. tularensis subsp. novicida.

The aim of this study was to determine the species and subspecies of a Francisella clinical isolate obtained from a human infection in Arizona. This aim was accomplished using multiple DNA-based approaches. We report that the clinical isolate has the molecular signature of $F$. tularensis subsp. novicida. Human disease events caused by F. tularensis subsp. novicida are rare, making this isolate of particular interest.

\section{Results and Discussion Clinical presentation}

In August of 2006, a 15-year-old male who had presented with swelling on alternating sides of the face and neck over the preceding two to three weeks reported to a hospital in Maricopa County, Arizona. The patient, who had prior treatment with penicillin with no relief of symptoms, had no fever and normal white blood counts. The patient was negative on screening tests for EBV, bartonellosis, toxoplasmosis, tuberculosis, and coccidioidomycosis; blood culture also was negative. The patient was admitted for continued monitoring and an infectious disease consult, and he was treated with ampicillin and clindamycin. Biopsies in the area of the right parotid gland revealed a reactive lymph node. A biopsy sample was obtained for examination by microscopy, culture, and molecular typing. Based on the results of culture (next section), antibiotic treatment for the patient was switched to doxycycline even as the patient was on his way to recovery. No risk factors for tularemia acquisition were identified during interviews of the patient and his mother.

Hospital records were examined for this patient and it was determined that he had presented three times to a local emergency room in February 2006. On first visit, the patient reported intermittent malaise for 3-4 days, myalgia, diffuse abdominal pain, nausea, vomiting, and one episode of diarrhea. Elevated WBC was noted and pleural effusion and prominent mesenteric lymph nodes were observed on CT scan. The patient was diagnosed with pneumonia and was sent home with a prescription for zithromax. Four days later, the patient returned to the emergency room with complaints of shortness of breath and left shoulder and chest pain, although his previous symptoms had resolved. Pleural effusion was noted on chest radiographs. The patient was treated with rocephin, sent home with a prescription for augmentin, and told to continue with zithromax. Two weeks later the patient visited a local ER again with chief complaint of hand and foot pain and was advised to take ibuprofen.

The patient and his mother were interviewed with regards to previous medical history, travel, and other risk factors for tularemia, but none were revealed. The patient reported no travel history outside of county of residence (Maricopa) for several years, no contact with any animals or unchlorinated water, no hunting, and no insect bites. The family, which lives in an urban setting, owns three dogs but reported no tick problems. A sibling previously 
owned a ferret which was given away and later died. However, the patient had no contact with the ferret, and no handlers of the ferret reported illness. The family reported that rats had been observed outside on the family's property. The patient reported that he mows the lawn for a neighbor, but denied running over any animal carcasses and reported that he otherwise prefers to stay indoors.

\section{Initial identification}

On culture, a light growth of Gram-negative rods was reported by a commercial lab, and was determined by biochemical tests to resemble Kingella species. Initial PCR analysis assigned the clinical isolate to F. tularensis. This finding was further confirmed by direct fluorescent antibody staining. The CDC in Fort Collins, CO, USA subsequently tested the isolate and reported that it was a " $F$. tularensis non-A, non-B subspecies."

\section{Molecular analyses}

Due to a lack of risk factors and the Select Agent status of F. tularensis, identifying the subspecies of this isolate was desirable. Because the isolate was neither of the two major F. tularensis subspecies, tularensis or holarctica, subspecies identification became of additional scientific interest. One possibility was that the isolate was not actually $F$. tularensis, but rather a closely-related but undefined Francisella species. To test this possibility, we subtyped the clinical isolate using multiple DNA-based approaches that provided increasing levels of resolution. Previous studies have indicated that analysis of the $16 \mathrm{~S}$ rDNA gene sequence is useful for examining the relationship of Francisella to other closely-related genera $[2,20]$; this gene fragment also can be amplified from unculturable nearneighbor species [2]. Our analysis of the 16S rDNA gene confirmed that the clinical isolate was a member of the $F$. tularensis group (Fig 1). Multi-locus Sequence Typing (MLST), which is effective at assigning unknown isolates of F. tularensis to one of the four subspecies [12], indicated that the clinical isolate clustered within the subspecies novicida clade; this clade was supported by high bootstrap values in the phylogenetic analysis (Fig 2). Within the novicida clade, the clinical isolate possessed a unique MLST genotype (Fig 2). Barns et al. [14] previously reported that primer sets targeting a putative succinate dehydrogenase locus were useful for discriminating among the subspecies of F. tularensis. Sequencing analysis of the amplicon generated with their primer sets indicated the clinical isolate was identical to that of several $F$. tularensis subspecies novicida isolates (data not shown). Finally, variable-number tandem repeat analysis utilizing 11 loci [21] grouped the clinical isolate with other F. tularensis subspecies novicida isolates (data not shown).

\section{Conclusion}

We conclude that the clinical isolate from this human case belongs to $F$. tularensis subsp. novicida. It is unclear if the hospitalization for abdominal pain and pneumonia six months earlier was related to the subsequent diagnosis of tularemia made from the lymph node biopsy. However, because this subspecies is known to exhibit low virulence, these findings suggest that this case may have been a lingering, chronic infection. Despite the fact that this subspecies is infrequently associated with disease in immunocompetent hosts, several cases have been documented [710] and F. tularensis subsp. novicida is considered a human pathogen and a Select Agent. Because infections by F. tularensis subsp. novicida may often lack clinical significance, the frequency of human infections may be underreported $[7,10,22]$. The rarity of this novicida subspecies in clinical settings makes each case study important by advancing our understanding of its role in disease and its genetic relationship with other $F$. tularensis subspecies.

\section{Methods \\ I6S rDNA and MLST Gene Sequencing}

Initial amplification of the $16 \mathrm{~S}$ rDNA gene was performed using the forward primer 27F.1G (5'-GAGRGTTTGATCMTGGCTCAG-3') and two reverse primers, 787Rb (5'GGACTACNRGGGTATCTAAT-3') and 1391-R (5'-GACGGGCGGTGTGTRCA-3'). Amplification was carried out in $10 \mu \mathrm{l}$ reactions containing $1 \times$ PCR buffer (Invitrogen, Carlsbad, CA), $2 \mathrm{mM} \mathrm{MgCl}_{2}$ (Invitrogen), $0.2 \mathrm{mM}$ each deoxynucleoside triphosphate (Invitrogen), $0.8 \mathrm{U}$ Platinum Taq polymerase (Invitrogen), and $1 \mu$ l DNA template. Thermal cycling conditions were $94^{\circ} \mathrm{C}$ for $5 \mathrm{~min}, 35$ cycles of $94^{\circ} \mathrm{C}$ for $30 \mathrm{~s}, 55^{\circ} \mathrm{C}$ for $30 \mathrm{~s}$ and $72^{\circ} \mathrm{C}$ for 1.5 min, and a final extension of $72^{\circ} \mathrm{C}$ for $5 \mathrm{~min}$. Multi-locus sequence typing (MLST) genes were amplified as described previously [12]. Sequencing of these 16S rDNA and MLST gene amplicons was carried out on an ABI 3100 (Applied Biosystems, Foster City, CA) using BigDye terminator cycle sequencing reagents (v. 3.1 Applied Biosystems).

\section{Nucleotide sequence accession numbers}

Nucleic acid sequences generated for this study were deposited in GenBank. Accession numbers for 16S rDNA sequences are as follows: Human isolate F. tularensis [GenBank:U867541], CA99 3549 F. tularensis subsp. novicida [GenBank:U867538], FSC 159 F. tularensis subsp. novicida-like [GenBank:U867537], GA99 3548 F. tularensis subsp. novicida [GenBank:U867539], AL97 2214 F. tularensis subsp. novicida [GenBank:U1867540]. Accession numbers for MLST gene fragment sequences are as follows: uup: [GenBank:U867519 to U867524]; aroA: [GenBank:U867525 to U867530]; atpA: [GenBank:U867531 to $\underline{\mathrm{U} 867536}$ ]; pgm: [GenBank: $\underline{\mathrm{U} 867548}$ to U867553]; tpiA: [GenBank:ㄴ867554 to U867559]; trpE: [GenBank:U867560 to $\underline{\mathrm{U} 867565]}$; parC: [GenBank: $\underline{\mathrm{U} 867542}$ to U867547] for isolates FSC 156, FSC 159, CA99 3549, GA99 3548, AL97 2214, and the human isolate, respectively. 


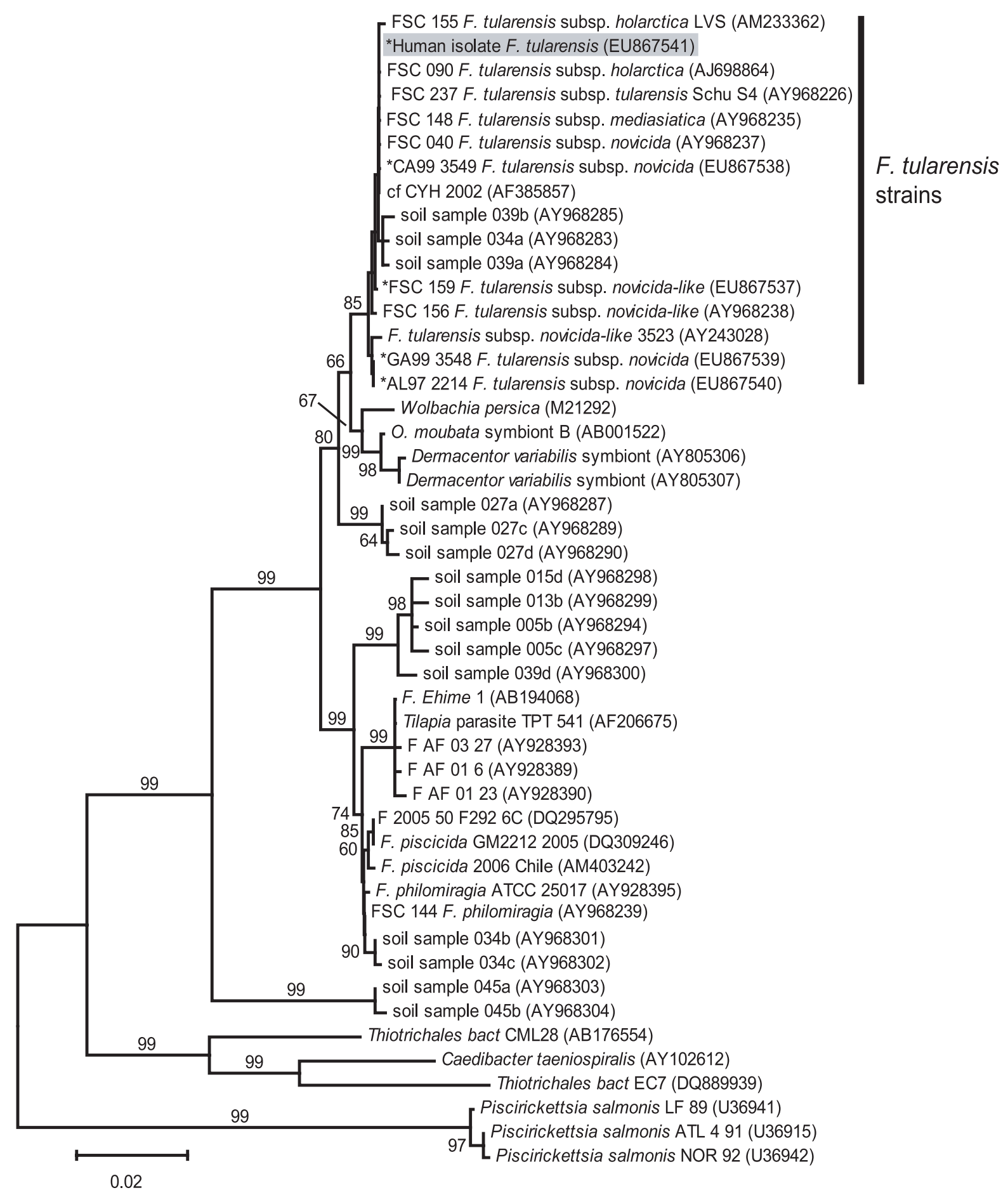

Figure I

Neighbor-joining phylogeny constructed from I6S rDNA gene sequences. Sequences were obtained from the clinical human isolate, other F. tularensis isolates, and isolates from related species. The tree, which was created using MEGA2 software [23], is midpoint rooted. Bootstrap values $\geq 60$ are presented and are based upon I,000 replicates. The human clinical isolate clusters with the $F$. tularensis strains; right vertical bar indicates $F$. tularensis clade. Sequences with an asterisk $(*)$ were generated as part of this study. All other sequences were obtained from GenBank. Accession numbers for all sequences are shown in parentheses. The scale bar, expressing mean character difference, corresponds to 0.02 substitutions per nucleotide position. 


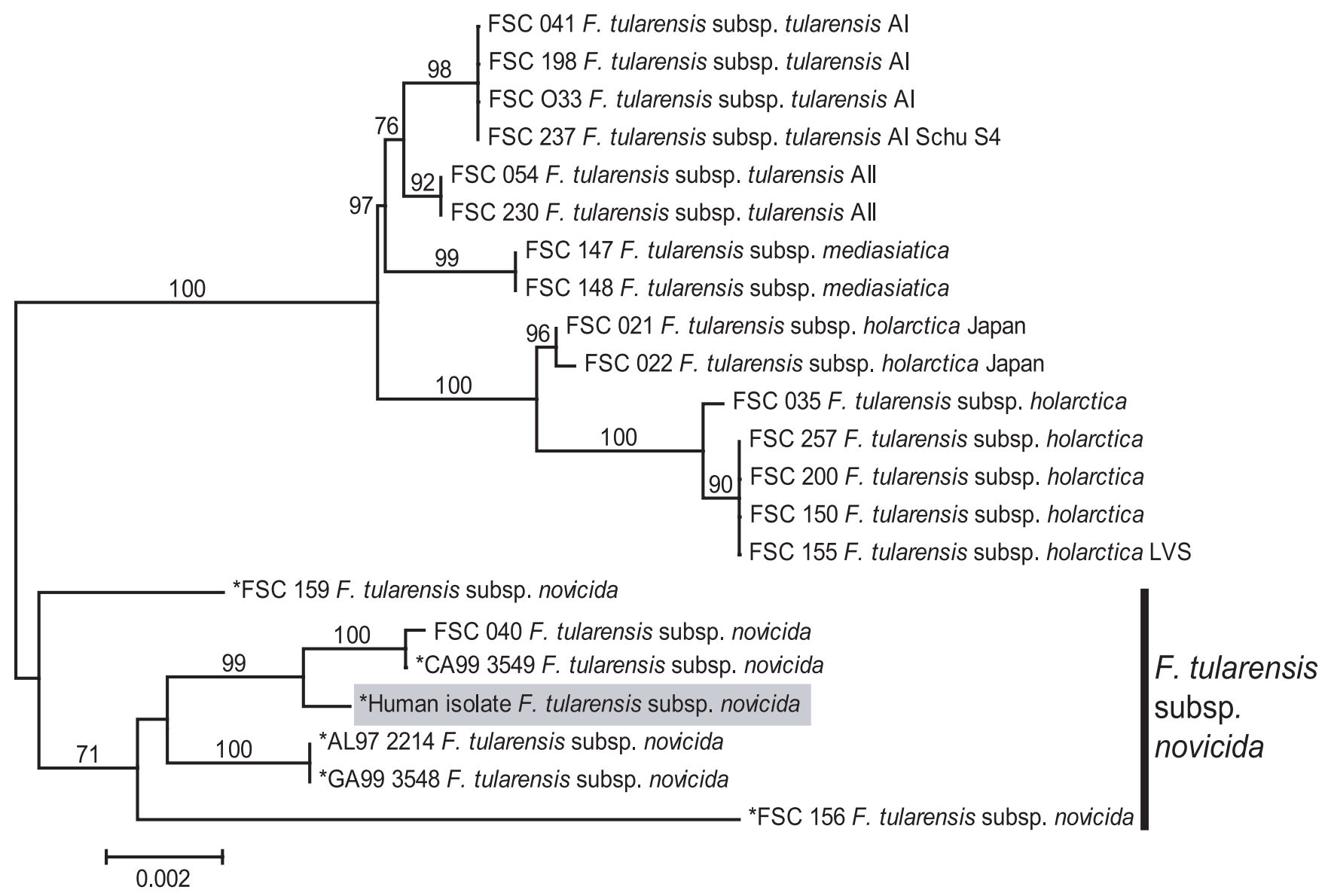

Figure 2

Neighbor-joining phylogeny constructed from concatenated MLST gene fragment sequences. Sequences were obtained from the clinical human isolate and other strains representing the four subspecies of $F$. tularensis. The tree, which was created using MEGA2 software [23], is midpoint rooted. Bootstrap values $\geq 60$ are presented and are based upon I,000 replicates. The human clinical isolate clusters with the $F$. tularensis subsp. novicida clade, which is indicated with the right vertical bar. Sequences with an asterisk (*) were generated as part of this study. All other sequences were obtained from GenBank and originated from a study by Svensson et al. [12]. The scale bar, expressing mean character difference, corresponds to 0.002 substitutions per nucleotide position.

\section{Competing interests}

The authors declare that they have no competing interests.

\section{Authors' contributions}

DNB carried out the molecular genetic studies, participated in the construction of the phylogenetic trees and drafted the manuscript. JLB carried out the molecular genetic studies. AJV participated in the design of the study and drafted the manuscript. TS, EL, AD, and TLS participated in the clinical study. RKA participated in the computational in silico data analysis. PK participated in data interpretation and drafted the manuscript. DMW assisted in the design of the study and drafted the manuscript. All authors read and approved of the final manuscript.

\section{Authors' information}

DNB, Ph.D., Northern Arizona University, Flagstaff, Arizona

TS, MPH, Maricopa County Department of Public Health, Phoenix, Arizona

AJV, Ph.D., Northern Arizona University, Flagstaff, Arizona

EL, DVM, Arizona Department of Health Services, Phoenix, Arizona

AD, MPH, Maricopa County Department of Public Health, Phoenix, Arizona 
TLS, BSN, Maricopa County Department of Public Health, Phoenix, Arizona

JLB, Northern Arizona University, Flagstaff, Arizona

RKA, M.S., Northern Arizona University, Flagstaff, Arizona

PK, Ph.D., Northern Arizona University, and Translational Genomics Research Institute, Flagstaff, Arizona

DMW*, Ph.D., Northern Arizona University, Flagstaff, Arizona

\section{Acknowledgements}

This work was funded by the Department of Homeland Security Science and Technology Directorate (NBCH207000I and HSHQDC-08-C-00 I58), the Pacific Southwest Regional Center of Excellence (Al065359), and the Cowden Endowment in Microbiology at Northern Arizona University. Note that the use of products/names does not constitute endorsement by the Department of Homeland Security of the United States. We thank Jeannine Petersen and James Schupp for helpful discussions.

\section{References}

I. Dennis DT, Inglesby TV, Henderson DA, I5 other authors: Tularemia as a biological weapon: medical and public health management. Working group on Civilian Biodefense. JAMA 2001, 285:2763-2773.

2. Keim P, Johansson A, Wagner DM: Molecular Epidemiology, Evolution, and Ecology of Francisella. Ann NY Acad Sci 2007, I 1 05:30-66.

3. Ottem KF, Nylund A, Karlsbakk E, Friis-Moller A, Krossoy B, Knappskog D: New species in the genus Francisella (Gammaproteobacteria; Francisellaceae); Francisella piscicida sp. nov. isolated from cod (Gadus morhua). Arch Microbiol 2007, I 88:547-550.

4. Farlow J, Wagner DM, Dukerich M, Stanley M, Chu M, Kubota K, Petersen J, Keim P: Francisella tularensis in the United States. Emerg Infect Dis 2005, I I: I835-184I.

5. Johansson A, Farlow J, Larsson P, Dukerich M, Chambers E, Bystrom M, Fox J, Chu M, Forsman M, Sjostedt A, Keim P: Worldwide genetic relationships among Francisella tularensis isolates determined by multiple-locus variable-number tandem repeat analysis. J Bacteriol 2004, I 86:5808-58I8.

6. Staples JE, Kubota KA, Chalcraft LG, Mead PS, Petersen JM: Epidemiologic and molecular analysis of human tularemia, United States, 1964-2004. Emerging Infectious Diseases 2006, | 2: | | |3- I | 18 .

7. Clarridge JE III, Raich TJ, Sjösted A, Sandström G, Darouiche RO, Shawar RM, Georghiou PR, Osting C, Vo L: Characterization of two unusual clinically significant Francisella strains. J Clin Microbiol 1996, 34:1995-2000.

8. Hollis DG, Weaver RE, Steigerwalt AG, Wenger JD, Moss CW, Brenner DJ: Francisella philomiragia comb. nov. (formerly Yersinia philomiragia) and Francisella tularensis biogroup novicida (formerly Francisella novicida) associated with human disease. J Clin Microbiol 1989, 27: I60I-I608.

9. Leelaporn A, Yongyod S, Limsrivanichakorn S, Yungyuen T, Kiratisin P: Francisella novicida bacteremia, Thailand. Emerg Infect Dis 2008, I 4:1935-1937.

10. Whipp MJ, Davis JM, Lum G, de Boer J, Zhou Y, Bearden SW, Petersen JM, Chu MC, Hogg G: Characterization of a novicidalike subspecies of Francisella tularensis isolated in Australia. J Med Microbiol 2003, 52:839-842.

II. Sjöstedt A: Family XVII. Francisellaceae, Genus I. Francisella. In Bergey's Manual of Systematic Bacteriology Brenner D: Springer-Verlag; 2003: I I I-I35.
12. Svensson K, Larsson P, Johansson D, Bystrom M, Forsman M, Johansson A: Evolution of subspecies of Francisella tularensis. J Bacteriol 2005, I 87:3903-3908.

13. Wenger JD, Hollis DG, Weaver RE, Baker CN, Brown GR, Brenner DJ, Broome CV: Infection caused by Francisella philomiragia (formerly Yersinia philomiragia). A newly recognized human pathogen. Ann Intern Med 1989, I I 0:888-892.

14. Barns SM, Grow CC, Okinaka RT, Keim P, Kuske CR: Detection of diverse new Francisella-like bacteria in environmental samples. Appl Environ Microbiol 2005, 7 I:5494-5500.

15. Officials following up on bacteria detection [http:// www.hcphes.org/hcpress/Bacteria\%20detection.pdf]

16. Kugeler KJ, Mead PS, McGowan KL, Burnham JM, Hogarty MD, Ruchelli E, Pollard K, Husband B, Conley C, Rivera T, et al: Isolation and characterization of a novel Francisella sp. from human cerebrospinal fluid and blood. J Clin Microbiol 2008, 46:2428-2431.

17. de la Puente-Redondo VA, del Blanco NG, Gutierrez-Martin CB, Garcia-Pena FJ, Rodriguez Ferri EF: Comparison of different PCR approaches for typing of Francisella tularensis strains. J Clin Microbiol 2000, 38: 1016-1022.

18. Farlow J, Smith KL, Wong J, Abrams M, Lytle M, Keim P: Francisella tularensis strain typing using multiple-locus, variablenumber tandem repeat analysis. J Clin Microbiol 200I, 39:3186-3192.

19. Johansson A, Ibrahim A, Goransson I, Eriksson U, Gurycova D, Clarridge JE, Sjostedt A: Evaluation of PCR-based methods for discrimination of Francisella species and subspecies and development of a specific PCR that distinguishes the two major subspecies of Francisella tularensis. J Clin Microbiol 2000, 38:4180-4185.

20. Forsman M, Sandstrom G, Sjostedt A: Analysis of I6S ribosomal DNA sequences of Francisella strains and utilization for determination of the phylogeny of the genus and for identification of strains by PCR. Int J Syst Bacteriol 1994, 44:38-46.

21. Vogler AJ, Birdsell D, Wagner DM, Keim P: An optimized, multiplexed multi-locus variable-number tandem repeat analysis system for genotyping Francisella tularensis. Lett Appl Microbiol 2009, 48: 140-144.

22. Bernard K, Tessier S, Winstanley J, Chang D, Borczyk A: Early recognition of atypical Francisella tularensis strains lacking a cysteine requirement. J Clin Microbiol 1994, 32:55 I-553.

23. Kumar S, Tamura K, Jakobsen IB, Nei M: MEGA2: molecular evolutionary genetics analysis software. Bioinformatics 200I, I 7:1244-1245.

\footnotetext{
Publish with BIo Med Central and every
scientist can read your work free of charge
"BioMed Central will be the most significant development for
disseminating the results of biomedical research in our lifetime. "
Sir Paul Nurse, Cancer Research UK
Your research papers will be:
• available free of charge to the entire biomedical community
- peer reviewed and published immediately upon acceptance
• cited in PubMed and archived on PubMed Central
Submit your manuscript here:
http://www.biomedcentral.com/info/publishing_adv.asp
} 